\title{
Composição química e digestibilidade in vitro da massa seca de cana-de-açúcar acrescida de ureia em diferentes tempos de estocagem
}

\author{
Chemical composition and "in vitro" dry mass digestibility of sugarcane with urea in \\ different storage times
}

\author{
REZENDE, Adauton Vilela de ${ }^{1}$; SENEDESE, Simone Silvia ${ }^{1}$; RABELO, Carlos \\ Henrique Silveira $^{2 *}$; NOGUEIRA, Denismar Alves ${ }^{3}$; VIEIRA, Paulo de Figueiredo ${ }^{1}$; \\ RABELO, Flávio Henrique Silveira ${ }^{4}$
}

\footnotetext{
${ }^{1}$ Universidade José do Rosário Vellano, Departamento de Zootecnia, Alfenas, Minas Gerais, Brasil.

${ }^{2}$ Universidade Estadual Paulista, Departamento de Zootecnia, Jaboticabal, São Paulo, Brasil.

${ }^{3}$ Universidade Federal de Alfenas, Departamento de Ciências Exatas, Alfenas, Minas Geais, Brasil.

${ }^{4}$ Universidade José do Rosário Vellano, Departamento de Agronomia, Alfenas, Minas Gerais, Brasil.

*Endereço para correspondência: carlos.zoo@hotmail.com
}

\section{RESUMO}

Objetivou-se com esta pesquisa avaliar a composição química e a digestibilidade in vitro da massa seca (MS) da cana-de-açúcar acrescida de ureia, mantida à sombra e sol em diferentes tempos de estocagem. $\mathrm{O}$ delineamento experimental utilizado foi inteiramente ao acaso em esquema fatorial $6 \times 2$, com seis tempos de estocagem após a mistura $(0 ; 2 ; 4 ; 6 ; 12$ e 24 horas) e dois locais de armazenamento (sombra e sol), e três repetições. A cana-de-açúcar utilizada apresentava 12 meses de desenvolvimento e foi desintegrada para aplicação da mistura (nove partes de ureia para uma de sulfato de amônio) a 1,0 kg/100,0 kg de cana-deaçúcar fresca. As amostragens realizadas com 12 horas de estocagem indicaram que houve acréscimo no teor de MS e de proteína bruta (PB) da cana-de-açúcar comparada ao momento da mistura (307,6 vs. 294,2 g/kg de MS e 115,2 vs. $99,3 \mathrm{~g} / \mathrm{kg}$ de MS, respectivamente), e o menor teor de fibra em detergente neutro (FDN) foi observado por volta de 12 horas de estocagem $(465,0 \mathrm{~g} / \mathrm{kg}$ de MS). Os coeficientes de digestibilidade in vitro da MS (DIVMS) variaram de 0,558 para 0,612 nos tempos 0 e 12 horas, respectivamente. O tempo de estocagem altera a composição química da cana-de-açúcar acrescida de ureia. O local de armazenamento altera o teor de massa seca e valores de $\mathrm{pH}$.

Palavras-Chave: nutrientes, proteína, Saccharum officinarum L., sulfato de amônio

\section{SUMMARY}

The objective of this research was to evaluate the chemical composition and in vitro dry mass (DM) digestibility of sugar cane with urea, maintained in the shade and sun, at different storage times. The utilized design was the completely randomized in a factorial scheme $6 \times 2$, that is, six storage times after the mixing $(0 ; 2 ; 4 ; 6 ; 12$ and 24 hours) and two storage location (shade and sun), with three replicates. The sugarcane utilized presented 12 months of development and was disintegrated for application of mixture (nine parts of urea for one of ammonium sulfate) to $1.0 \mathrm{~kg} / 100.0 \mathrm{~kg}$ of fresh sugarcane. The samples taken with 12 hours of storage indicated that was an increase in the content of DM and crude protein (CP) of sugar cane compared to the moment of the mixture $(307.6$ vs. $294.2 \mathrm{~g} / \mathrm{kg}$ of DM and 115.2 vs. $99.3 \mathrm{~g} / \mathrm{kg}$ of $\mathrm{DM}$, respectively), and the smaller content of neutral detergent fiber (NDF) was observed around of 12 hours of storage $(465.0 \mathrm{~g} / \mathrm{kg}$ of DM). The coefficients of in vitro dry mass digestibility (IVDMD) ranged of 0.558 to 0.612 in the times 0 and 12 hours, respectively. The length of storage changes the chemical composition of sugar cane plus urea. The storage location changes the dry mass content and $\mathrm{pH}$ values.

Keywords: ammonium sulfate, nutrients, protein, Saccharum officinarum L. 


\section{INTRODUÇÃO}

No Brasil, a pastagem é sem dúvida o ambiente mais econômico para produção animal. Entretanto, no período de seca em determinadas regiões do país, não há alimento em quantidade e qualidade suficiente nas pastagens para maximizar os índices produtivos (COSTA et al., 2008). Neste contexto, a cana-de-açúcar (Saccharum officinarum) tem sido difundida entre os produtores como uma alternativa viável para alimentação dos animais, por ser uma cultura de baixo risco, apresentar reduzido custo de produção de massa seca por unidade de área e maior disponibilidade e valor nutritivo no período de escassez de forragem (NUSSIO, 2003; OLIVEIRA et al., 2008).

A cana-de-açúcar fornece alta quantidade de energia aos animais (MORENO et al., 2010) e grande parte desta está contida nos açúcares solúveis. Contudo, quando ensilada há depreciação no valor nutritivo em virtude da intensa atividade de leveduras que convertem açúcares a etanol, gás carbônico $\left(\mathrm{CO}_{2}\right)$ e água, o que causa reduções de até $70 \%$ no teor de carboidratos solúveis, aumento nos componentes da parede celular e perdas de MS (PEDROSO et al., 2005). A utilização desta forrageira na forma in natura é uma opção interessante, ao se levar em consideração as limitações no que se refere ao baixo teor de proteína e minerais, principalmente cálcio e fósforo (SILVEIRA et al., 2009), portanto faz-se necessária a suplementação com uma fonte proteica e mineral.

Por isso, tem sido proposta a utilização de nitrogênio não-proteico (NNP), especificamente a ureia, para corrigir o baixo teor de proteína da cana-deaçúcar e desta maneira melhorar o balanceamento de nutrientes deste alimento (GESUALDI et al., 2001;
SOUZA et al., 2002). Este processo eleva os conteúdos de nitrogênio $(\mathrm{N})$ no alimento o que aumenta a disponibilidade aos micro-organismos ruminais (SOUZA et al., 2001), com atuação mais eficaz destes sobre $o$ substrato alimentício em virtude da sincronização entre disponibilidade de energia e de proteína (CARMO et al., 2001; SILVEIRA et al., 2009). Vale destacar que a utilização da ureia como fonte de amônia apresenta fácil manuseio e baixo custo (PIRES et al., 2004; FERREIRA et al., 2007) e por isso, tem sido uma excelente alternativa para corrigir a deficiência proteica (OLIVEIRA JÚNIOR et al., 2004; CARVALHO et al., 2011).

Neste sentido, objetivou-se avaliar a composição química e a digestibilidade in vitro da massa seca da cana-deaçúcar acrescida de ureia, mantida à sombra e ao sol em diferentes tempos de estocagem.

\section{MATERIAL E MÉTODOS}

O experimento foi conduzido no setor de Forragicultura da Faculdade de Zootecnia na Universidade José do Rosário Vellano (UNIFENAS), Campus de Alfenas - MG. A variedade de canade-açúcar utilizada no estudo foi RB72454, com 12 meses de desenvolvimento vegetativo, com presença de grau Brix = $18,2^{\circ}$. A determinação do grau Brix antecedeu o dia do corte e foi realizada mediante utilização de um refratômetro de campo, o que forneceu diretamente a porcentagem de sólidos solúveis do caldo da cana-de-açúcar.

A cana-de-açúcar foi colhida manualmente no mês de setembro de 2007 (horário de corte - 10hs) e desintegrada em picadeira estacionária sem retirada da palha para de obter 
partículas com tamanho próximo a dois centímetros para posterior aplicação da ureia. A mistura foi formulada em uma relação de nove partes de ureia $\left[\mathrm{CO}\left(\mathrm{NH}_{2}\right)_{2}\right]$ para uma de sulfato de amônio $\left[\left(\mathrm{NH}_{4}\right)_{2} \mathrm{SO}_{4}\right]$ e foi homogeneizada à cana-de-açúcar (aplicação de 1,0kg da mistura em 100kg de cana-de-açúcar fresca). Posteriormente foram confeccionados amontoados da mistura cana + ureia na mesma proporção, em porções de $15 \mathrm{~kg}$, o que simulou o fornecimento deste volumoso em cochos de alvenaria.

O delineamento experimental utilizado foi o inteiramente ao acaso em esquema fatorial $6 \times 2$, e os tratamentos distribuídos em seis tempos de estocagem após a mistura cana + ureia $(0 ; 2 ; 4 ; 6 ; 12$ e 24 horas) em dois locais (sombra e sol), com três repetições, em um total de 36 parcelas. Para isso, os amontoados foram confeccionados de tal forma que havia três montes de cana + ureia ao sol e três amontoados da mistura à sombra (abaixo de um galpão coberto, porém, aberto lateralmente) para cada tempo de exposição aeróbia.

Após a confecção dos amontoados foi aferida a temperatura de cada parcela, mediante a utilização de um termômetro analógico inserido a $15 \mathrm{~cm}$ de profundidade no centro das massas (Tabela 1).

Tabela 1. Temperatura $\left({ }^{\circ} \mathrm{C}\right)$ das massas de cana-de-açúcar em função dos tratamentos

\begin{tabular}{ccc}
\hline $\begin{array}{c}\text { Tempo de } \\
\text { estocagem (horas) }\end{array}$ & Sol & Sombra \\
\hline 0 & 23 & 23 \\
2 & 23 & 20 \\
4 & 20 & 20 \\
6 & 23 & 19 \\
12 & 19 & 18 \\
24 & 31 & 25 \\
\hline
\end{tabular}

Os parâmetros utilizados para avaliação da composição bromatológica da cana-deaçúcar foram massa seca (MS), proteína bruta (PB) e nitrogênio amoniacal $\left(\mathrm{N}-\mathrm{NH}_{3}\right)$ determinados conforme as técnicas descritas por Silva \& Queiroz (2002). Os teores de fibra em detergente neutro (FDN) e fibra em detergente ácido (FDA) foram determinados conforme Van Soest (1967). O pH foi determinado por meio da utilização de um peagâmetro Beckman Expandomatic SS-2 ${ }^{\circledR}$ (SILVA \& QUEIROZ, 2002). Para isso, foram colhidas nove gramas de amostras da mistura cana + ureia em cada parcela, que permaneceram em repouso por 20 minutos em $60 \mathrm{~mL}$ de água destilada para posterior determinação. Os coeficientes de digestibilidade in vitro da massa seca (DIVMS) foram determinados de acordo com o método de dois estágios proposto por Tilley \& Terry (1963).

A análise estatística dos dados foi realizada por meio do software SISVAR $^{\circledR} \quad$ (FERREIRA, 2008), comparando-se as médias pelo teste $\mathrm{F}$ e o tempo de estocagem por análise de regressão $(\alpha=0,05)$, decompondo-se as equações ao efeito de ordem linear, quadrática e cúbica, com posterior ajuste de regressões. A interação entre os dados também foi estudada, contudo não houve efeito sobre qualquer variável.

\section{RESULTADOS E DISCUSSÃO}

Os valores de $\mathrm{pH}$ diminuíram com o decorrer do tempo de estocagem $(\mathrm{P}<0,01)$, com valores de 6,54 na primeira avaliação (tempo 0 ) e 4,64 após 24 horas de estocagem (Tabela 2). Explica-se este fato pela atuação de micro-organismos oportunistas e indesejáveis sobre as massas de cana-de-açúcar, principalmente 
Rev. Bras. Saúde Prod. Anim., Salvador, v.13, n.1, p.25-34 jan/mar, 2012 http://www.rbspa.ufba.br ISSN 15199940

leveduras, que são em maior parte responsáveis pela deterioração aeróbia (SIQUEIRA et al., 2005), ao promoverem a acidificação do meio devido à conversão de açúcares em ácidos orgânicos, $\mathrm{CO}_{2}$ e $\mathrm{H}_{2} \mathrm{O}$, o que culmina no decréscimo dos valores de $\mathrm{pH}$.

Contudo, o $\mathrm{pH}$ apresentou relativa demora para diminuir ao longo do tempo, o que pode estar associado à ação antimicrobiana exercida pela aplicação de ureia e cujo efeito foi observado por Zanine et al. (2006), que ao trabalharem com bagaço de cana-deaçúcar tratado com ureia na base da massa seca em 1,$0 ; 2,0$ e $3,0 \mathrm{~kg} / 100 \mathrm{~kg}$, notaram valores de mofos e leveduras de $2,2 \times 10^{5}, 2,0 \times 10^{4}$ e $3,7 \times 10^{3}$, respectivamente.

Tabela 2. Composição química de cana-de-açúcar tratada com ureia durante os tempos de estocagem e equações de regressão

\begin{tabular}{lcccccclcc}
\hline \multirow{2}{*}{ Item $^{1}$} & \multicolumn{7}{c}{ Tempo (horas) } & & \multicolumn{2}{c}{ Equação } & \multirow{2}{*}{$\mathrm{r}^{2}$} \\
\cline { 2 - 7 } & 0 & 2 & 4 & 6 & 12 & 24 & & 0,836 \\
\hline $\mathrm{pH}$ & 6,54 & 6,38 & 6,22 & 6,06 & 5,59 & 4,64 & $\mathrm{Y}=6,539-0,079 \mathrm{x}$ & - \\
$\mathrm{N}-N H_{3}$ & 20,60 & 21,15 & 22,30 & 20,95 & 22,35 & 22,60 & $\mathrm{Y}=232,92$ & \\
$\mathrm{MS}$ & 301,73 & 303,61 & 306,48 & 309,61 & 307,41 & 307,15 & $\mathrm{Y}=301,73-0,18 \mathrm{x}+7,47 \mathrm{x}^{2}$ & 0,808 \\
$\mathrm{~PB}$ & 99,30 & 105,46 & 110,26 & 113,70 & 115,86 & 83,46 & $\mathrm{Y}=99,30+3,42 \mathrm{x}-0,17 \mathrm{x}^{2}$ & 0,939 \\
$\mathrm{FDN}$ & 475,77 & 473,13 & 462,15 & 463,25 & 473,73 & 466,70 & $\mathrm{Y}=475,77+0,87 \mathrm{x}-19,61 \mathrm{x}^{2}$ & 0,846 \\
$\mathrm{FDA}$ & 242,70 & 235,60 & 223,80 & 230,75 & 237,15 & 227,55 & $\mathrm{Y}=21,66$ & - \\
DIVMS & 0,558 & 0,575 & 0,589 & 0,600 & 0,613 & 0,550 & $\mathrm{Y}=0,55+0,009 \mathrm{x}-0,0004 \mathrm{x}^{2}$ & 0,757 \\
\hline
\end{tabular}

$\mathrm{MS}=$ massa seca, $\mathrm{PB}=$ proteína bruta, $\mathrm{FDN}=$ fibra em detergente neutro, $\mathrm{FDA}=$ fibra em detergente ácido, DIVMS $=$ digestibilidade in vitro da massa seca.

${ }^{1}$ Os dados estão expressos em $\mathrm{g} / \mathrm{kg}$ de MS, exceto os valores de $\mathrm{pH}$, MS (expressos em g/kg de MV) e DIVMS (kg/kg de MS).

Ao se comparar os locais de estocagem, notou-se menor valor $(\mathrm{P}<0,05)$ de $\mathrm{pH}$ quando as massas permaneceram expostas ao sol (Tabela 3), o que pode estar associado à produção de ácidos orgânicos, $\mathrm{CO}_{2}$ e $\mathrm{H}_{2} \mathrm{O}$ por micro-organismos deterioradores, que possivelmente encontraram melhor ambiente para atuação sobre o substrato devido às maiores temperaturas neste local. Micro-organismos deterioradores, principalmente leveduras, são os maiores responsáveis pela redução de carboidratos solúveis em cana-de-açúcar (LOPES \& EVANGELISTA, 2010) a produtos de qualidade nutritiva inferior, como ácido acético e butírico. Este evento contribui para que o alimento se torne menos palatável aos animais, haja vista que o $\mathrm{pH}$ diminui devido à formação destes compostos, além do que, a principal fonte de energia proveniente da cana-deaçúcar (carboidratos solúveis) diminui consideravelmente após o corte.

As concentrações de MS, PB e FDN foram alteradas pelo tempo de estocagem em que a mistura cana + ureia foi submetida $(\mathrm{P}<0,01)$, e houve efeito do local de estocagem somente sobre o teor de MS $(\mathrm{P}<0,05)$. Notou-se resposta quadrática no teor de MS em função do tempo de estocagem, em que os menores teores de MS foram verificados no momento da mistura cana + ureia (tempo 
0) e após 2 horas de estocagem (301,7 e $303,6 \mathrm{~g} / \mathrm{kg}$ de massa verde - MV), com acréscimo após estes tempos (Tabela 2).

Os menores teores de MS observados nas primeiras horas de estocagem estão associados à aplicação da ureia, pois segundo Cândido et al. (1999), materiais que são tratados com fonte de nitrogênio podem absorver umidade do ambiente devido ao elevado poder higroscópico da ureia.

Tabela 3. Composição química expresso a com base na MS em $\mathrm{g} / \mathrm{kg}$ ), nitrogênio amoniacal $\left(\mathrm{N}-\mathrm{NH}_{3}\right)$ e DIVMS $(\mathrm{kg} / \mathrm{kg})$ da mistura cana + ureia exposta a sombra e ao sol

\begin{tabular}{lccc}
\hline \multirow{2}{*}{ Item } & \multicolumn{2}{c}{ Ambiente $^{1}$} & \multicolumn{1}{c}{$\mathrm{CV}$} \\
\cline { 2 - 3 } & Sombra & Sol & $(\%)$ \\
\hline $\mathrm{pH}$ & $6,03^{\mathrm{a}}$ & $5,77^{\mathrm{b}}$ & 3,22 \\
$\mathrm{MS}$ & $301,5^{\mathrm{b}}$ & $306,7^{\mathrm{a}}$ & 2,28 \\
$\mathrm{~PB}$ & $102,7^{\mathrm{a}}$ & $106,2^{\mathrm{a}}$ & 10,44 \\
$\mathrm{FDN}$ & $467,4^{\mathrm{a}}$ & $477,5^{\mathrm{a}}$ & 3,12 \\
$\mathrm{FDA}$ & $227,9^{\mathrm{a}}$ & $238,0^{\mathrm{a}}$ & 7,99 \\
$\mathrm{~N}^{\mathrm{N}}$ & $2,17^{\mathrm{a}}$ & $2,16^{\mathrm{a}}$ & 13,2 \\
DIVMS & $0,526^{\mathrm{a}}$ & $0,563^{\mathrm{a}}$ & 5,14
\end{tabular}

${ }^{\mathrm{T}}$ Médias seguidas de mesma letra dentro das linhas não diferem entre si pelo teste $\mathrm{F}(\alpha=0,05)$.

$\mathrm{CV}=$ coeficiente de variação.

O maior teor de MS verificado após 12 horas de estocagem $(307,4 \mathrm{~g} / \mathrm{kg}$ de MV) deve-se à desidratação da mistura cana + ureia, que ao perder umidade para o ambiente contribui proporcionalmente para o acréscimo da MS.

Para o fator de estudo ambiente, verificou-se maior teor de MS nos montes expostos ao sol, o que era esperado, pois o meio propiciou maior evaporação de água além do calor gerado pela atuação de micro- organismos indesejáveis, o que refletiu em maior teor de MS (Tabela 3 ).

$\mathrm{O}$ estudo de regressão demonstrou ser quadrático o comportamento da variável PB em resposta ao tempo de estocagem, cuja variação foi de $115,8 \mathrm{~g} / \mathrm{kg}$ de $\mathrm{MS}$, com 12 horas de estocagem a $83,5 \mathrm{~g} / \mathrm{kg}$ de MS em 24 horas de repouso. O acréscimo no teor de PB pode estar relacionado ao desenvolvimento de micro-organismos indesejáveis (cuja constituição é proteica) na cana-deaçúcar, o que contribuiu para o aumento desta fração no momento da análise (Tabela 2).

No entanto, nota-se que após 12 horas de estocagem houve perda de $\mathrm{N}$, possivelmente devido à ação de microorganismos e, como o principal modo de retenção da ureia ao material é na forma de hidróxido de amônia, esta é passível de volatilização, o que leva ao decréscimo no teor de PB da cana-deaçúcar. Conforme descrito por Rosa \& Fadel (2001), a ureia quando aplicada em qualquer material é rapidamente hidrolisada, o que pode induzir a elevadas taxas de perda de $\mathrm{N}_{-} \mathrm{NH}_{3}$ por volatilização, o que é dependente da temperatura e umidade do material, assim como da quantidade e forma pela qual a ureia é aplicada.

No que se refere ao ambiente de estocagem, a expectativa seria de que a cana-de-açúcar exposta ao sol perderia maior quantidade de $\mathrm{N}$ por volatilização, entretanto esta premissa não ocorreu, e ficou demonstrado que o local de estocagem desta gramínea não influenciou o teor de $\mathrm{PB}$ e $\mathrm{N}-\mathrm{NH}_{3}$ (Tabela 3).

Pelos tempos de estocagem verificados neste trabalho, notou-se ajuste quadrático da variável FDN, em que o maior teor $(475,7 \mathrm{~g} / \mathrm{kg}$ de $\mathrm{MS})$ foi relatado no momento da mistura cana + ureia ( 0 hora), pois houve decréscimo nesta variável até 4 horas de estocagem, que 
alcançou 462,1g/kg de MS (Tabela 2). Este resultado, possivelmente, pode ser explicado pela ação da urease que na presença de água (existente na massa verde) hidrolisa a ureia que é desdobrada em amônia e ao se ligar à água forma o hidróxido de amônio, que é capaz de solubilizar os componentes da parede celular, principalmente a hemicelulose, o que reduz o teor de FDN do material, e assim pode refletir positivamente na digestibilidade dos constituintes celulares (ROSA \& FADEL, 2001).

Após 4 horas de estocagem houve tendência de aumento no teor de FDN com acréscimo de $11,6 \mathrm{~g} / \mathrm{kg}$ de MS até 12 horas de repouso $(473,7 \mathrm{~g} / \mathrm{kg}$ de MS), conforme a Tabela 2. Este resultado possivelmente está relacionado à ação de micro-organismos deterioradores que utilizam os carboidratos solúveis como substratos para seu desenvolvimento, o que reflete em maior participação de carboidratos fibrosos na massa pelo efeito de concentração e conseqüente aumento percentual no teor de FDN, conforme descrito por Siqueira et al. (2009).

A fração FDA que contém celulose e lignina apresenta baixa degradabilidade ruminal, o que pode afetar em maior ou menor grau o desempenho dos animais a depender da dieta total. Neste estudo, a concentração de FDA da cana-deaçúcar não foi alterada por nenhum dos fatores avaliados $(\mathrm{P}>0,05)$, o que indica que esta forrageira pode permanecer em ambos locais sem alteração em seus teores, e o mesmo foi observado quando se comparou a participação de nitrogênio amoniacal $\left(\mathrm{N}^{\left.-\mathrm{NH}_{3}\right)}\right.$, conforme as Tabelas 2 e 3 . Os valores encontrados neste trabalho acham-se abaixo dos reportados por Carvalho et al. (2006) que utilizaram com bagaço de cana amonizado com ureia.

Os coeficientes de digestibilidade in vitro da massa seca (DIVMS) foram alterados $(\mathrm{P}<0,01)$ somente em função dos tempos de estocagem. Pelos resultados obtidos nesta pesquisa, foi observado aumento na DIVMS até 12 horas $(0,613)$ após a mistura cana + ureia, no entanto a partir desse momento houve redução nestes coeficientes (Tabela 2).

A maior DIVMS obtida até 12 horas de estocagem pode ser explicada pelos mesmos comportamentos observados para os teores de PB e FDN supracitados até este mesmo período de 12 horas, ou seja, o aumento na concentração de $\mathrm{PB}$ disponibiliza maior quantidade de $\mathrm{N}$ aos micro-organismos do rúmen, o que melhora a eficiência de utilização do alimento devido à sincronização com a disponibilidade de energia (principal fonte - carboidratos solúveis). O menor valor observado na DIVMS ocorreu 24 horas após a mistura $(0,550)$ em virtude do baixo teor de $\mathrm{PB}$ e alta concentração de fibra (FDN), o que está correlacionado negativamente com a digestibilidade do material (MERTENS, 1987). Este resultado está relacionado à ação degradadora dos álcalis sobre os complexos lignocelulósicos dos volumosos tratados com produtos alcalinos, que solubilizam parte da hemicelulose, expande a celulose e assim a fração fibrosa torna-se de melhor qualidade (RIBEIRO et al., 2009). De acordo com Wilson \& Kennedy (1996), quando o suprimento de $\mathrm{N}$ não atende aos requerimentos microbianos, ocorre limitação do crescimento desses micro-organismos e redução da digestão da parede celular, o que diminui $o$ consumo e a digestibilidade da MS.

Entretanto, a redução nos coeficientes de DIVMS observada após 12 horas da mistura pode ser explicada principalmente devido ao decréscimo na concentração de carboidratos solúveis e no teor de $\mathrm{PB}$, haja vista que a principal 
Rev. Bras. Saúde Prod. Anim., Salvador, v.13, n.1, p.25-34 jan/mar, 2012 http://www.rbspa.ufba.br ISSN 15199940

fonte de energia da cana-de-açúcar está na forma de sacarose. Desta forma, micro-organismos deterioradores (leveduras e fungos filamentosos) atuam sobre esta fração, o que reflete percentualmente em maiores teores de fibra (carboidratos estruturais), que apresentam baixa digestibilidade. Conforme relatado por Van Soest (1994), a fração fibrosa em alta porcentagem afeta negativamente a digestibilidade do alimento. E ainda, de acordo com Lucci et al. (2006), em dietas com cana-de-açúcar como alimento base para ruminantes, evidencia-se dependência dos teores dietéticos de $\mathrm{N}$ para aproveitamento adequado do alimento. Maiores taxas de digestibilidade da MS foram direta e positivamente relacionadas à qualidade e quantidade de suplemento nitrogenado incluído nas rações, fato devido à digestão no rúmen depender da interação energia-nitrogênio.

Os resultados de DIVMS obtidos nesta pesquisa em 12 horas de estocagem $(0,613)$ foram superiores aos verificados por Lucci et al. (2006) que relataram degradabilidade efetiva da MS de 0,523 e por Lopes et al. (2007), que reportaram coeficiente de 0,459 em silagem de canade-açúcar tratada com 1,5\% de ureia.

A ureia destaca-se por ser uma boa fonte de $\mathrm{N}$ e, demonstra-se economicamente viável na conservação da cana-de-açúcar, pois atua positivamente na redução dos teores de fibra, além de contribuir intensamente no acréscimo de PB no alimento e aumentar a digestibilidade in vitro deste, até 12 horas após a mistura.

O tempo de estocagem altera a composição química da cana-de-açúcar acrescida de ureia, assim como o local de armazenamento altera o teor de massa seca e valores de $\mathrm{pH}$.

\section{REFERÊNCIAS}

CÂNDIDO, M.J.D.; NEIVA, J.N.M.; PIMENTEL, J.C.M.; VASCONSELOS, V.R.; SAMPAIO, E.M.; NETO, J.M. Avaliação do Valor Nutritivo do Bagaço de Canade-açúcar Amonizado com Uréia.

Revista Brasileira de Zootecnia, v.28, n.5, p.928-935, 1999.

CARMO, C.A.; BERCHIELLI, T.T.; ANDRADE, P.; ZEOLA, N.M.B.L. Degradabilidade da matéria seca e fibra em detergente neutro da canade-açúcar (Saccharum spp) com diferentes fontes de proteína. Revista Brasileira de Zootecnia, v.30, n.6, p.2126-2133, 2001.

CARVALHO, G.G.P.; PIRES, A.J.V.; VELOSO, C.M.; MAGALHÃES, A.F.; FREIRE, M.A.L.; SILVA, F.F.; SILVA, R.R.; CARVALHO, B.M.A. Valor nutritivo do bagaço de cana-deaçúcar amonizado com quatro doses de uréia. Pesquisa Agropecuária Brasileira, v.41, n.1, p.125-132, 2006.

CARVALHO, G.G.P.; GARCIA, R.; PIRES, A.J.V.; DETMANN, E.; SILVA, R.R.; PEREIRA, M.L.A.; SANTOS, A.B.; PEREIRA, T.C.J Metabolismo de nitrogênio em novilhas alimentadas com dietas contendo cana-de-açúcar tratada com óxido de cálcio. Revista Brasileira de Zootecnia, v.40, n.3, p.622-629, 2011.

COSTA, C.; MEIRELLES, P.R.L.; SILVA, J.J. Alternativas para contornar a estacionalidade de produção de forragens. Veterinária e Zootecnia, v.15, n.2, p.193-203, 2008. 
Rev. Bras. Saúde Prod. Anim., Salvador, v.13, n.1, p.25-34 jan/mar, 2012 http://www.rbspa.ufba.br ISSN 15199940

FERREIRA, D.A.; GONÇALVES, L.C.; MOLINA, L.R.; CASTRO NETO, A.G.; TOMICH, T.R. Características de fermentação da silagem de cana-deaçúcar tratada com uréia, zeólita, inoculante bacteriano e inoculante/enzimático. Arquivo Brasileiro de Medicina Veterinária e Zootecnia, v.59, p.423-433, 2007.

FERREIRA, D.F. SISVAR: um programa para análises e ensino de estatística.

Revista Científica Symposium, Lavras, v.6, n.2, p.36-41, 2008.

GESUALDI, A.C.L.S.; SILVA, J.F.C.; VASQUEZ, H.M.; ERBESDOBLER, E.D. Efeito da amonização sobre a composição, a retenção de nitrogênio e a conservação do bagaço e da ponta de cana-de-açúcar. Revista Brasileira de Zootecnia, v.30, n.2, p.508-517, 2001.

LOPES, J.; EVANGELISTA, A.R.; ROCHA, G.P. Valor nutricional da silagem de cana-de-açúcar acrescida de uréia e aditivos absorventes de umidade.

Revista Brasileira de Zootecnia, v.36, n.4, p.1155-1161, 2007. (suplemento)

LOPES, J.; EVANGELISTA, A.R. Características bromatológicas, fermentativas e população de leveduras de silagens de cana-de-açúcar acrescidas de uréia e aditivos absorventes de umidade. Revista Brasileira de Zootecnia, v.39, n.5, p.984-991, 2010.

LUCCI, C.S.; VALVASORI, E.; CAPEZZUTO, A.; LOPES, R.; FONTOLAN, V.; BUFFARAH, G.; PEIXOTO-JÚNIOR, K.C.

Digestibilidade in situ de cana-de-açúcar (Saccharum officinarum) nas formas natural ou ensilada, adicionadas ou não de uréia. Brazilian Journal of Veterinary Research and Animal Science, v.43, n.4, p.502-509, 2006.
MERTENS, D.R. Predicting intake and digestibility using mathematical models of ruminal function. Journal of Animal Science, v.64, n.5, p.1548-1558, 1987.

MORENO, G.M.B.; SILVA SOBRINHO, A.G.; LEÃO, A.G.; LOUREIRO, C.M.B.; PEREZ, H.L.; ROSSI, R.C. Desempenho, digestibilidade e balanço de nitrogênio em cordeiros alimentados com silagem de milho ou cana-de-açúcar e dois níveis de concentrado. Revista Brasileira de Zootecnia, v.39, n.4, p.853-960, 2010.

NUSSIO, L.G. Cana: depois de se impor em pequenos confinamentos, ela começa a atrair os grandes. Para isso tem de vencer o desafio da ensilagem. DBO Rural, v.22, n.272, p.104-112, 2003.

OLIVEIRA JR., R.C.; PIRES, A.V.; FERNANDES, J.J.R.; SUSIN, I.; SANTOS, F.A.P.; ARAÚJO, R.C. Substituição total do farelo de soja por uréia ou amiréia, em dietas com alto teor de concentrado, sobre a amônia ruminal, os parâmetros sanguíneos e o metabolismo do nitrogênio em bovinos de corte. Revista Brasileira de Zootecnia, v.33, n.3, p.738-748, 2004.

OLIVEIRA, M.D.S.; BARBOSA, J.C.; MOTA, D.A.; ANDRADE, A.T. Efeito da hidrólise com cal virgem sobre a composição bromatológica da cana-deaçúcar. Veterinária Notícias, v.14, n.1, p.9-17, 2008.

PEDROSO, A.F.; NUSSIO, L.G.; PAZIANI, S.F.; LOURES, D.R.S.; IGARASI, M.S.; COELHO, R.M.; PACKER, I.H.; HORII, J.; GOMES, L.H. Fermentation and epiphytic microflora dynamics in sugar cane silage. Scientia Agricola, v.62, n.5, p.427-432, 2005. 
Rev. Bras. Saúde Prod. Anim., Salvador, v.13, n.1, p.25-34 jan/mar, 2012 http://www.rbspa.ufba.br ISSN 15199940

PIRES, A.V.; OLIVEIRA JR.; R.C.; FERNANDES, J.J.R.; SUSIN, I.; SANTOS, F.A.P.; ARAÚJO, R.C.; GOULART, R.C.D. Substituição do farelo de soja por uréia ou amiréia na dieta de bovinos de corte confinados. Pesquisa Agropecuária Brasileira, v.39, n.9, p.937-942, 2004.

RIBEIRO, L.S.O.; PIRES, A.J.V.; PINHO, B.D.; CARVALHO, G.G.P.; FREIRE, M.A.L. Valor nutritivo da cana-de-açúcar hidrolisada com hidróxido de sódio ou óxido de cálcio. Arquivo Brasileiro de Medicina Veterinária e Zootecnia, v.61, n.5, p.1156-1164, 2009.

ROSA, B.; FADEL, R. Uso de amônia anidra e de uréia para melhorar o valor alimentício de forragens conservadas. In: SIMPÓSIO SOBRE PRODUÇÃO E UTILIZAÇÃO DE FORRAGENS CONSERVADAS, 2001. Maringá. Anais... Maringá: UEM/CCA/DZO, 2001. p.41-63.

SILVA, D.J.; QUEIROZ, A.C. Análise de alimentos: métodos químicos e biológicos. 3.ed. Viçosa: Universidade Federal de Viçosa, 2002. 235p.

SILVEIRA, R.N.; BERCHIELLI, T.T.; CANESIN, R.C.; MESSANA, J.D.; FERNANDES, J.J.R.; PIRES, A.V. Influência do nitrogênio degradável no rúmen sobre a degradabilidade in situ, os parâmetros ruminais e a eficiência de síntese microbiana em novilhos alimentados com cana-de-açúcar. Revista

Brasileira de Zootecnia, v.38, n.3, p.570-579, 2009.
SIQUEIRA, G.R.; BERNARDES, T.F.; REIS, R.A. Instabilidade aeróbia de silagens: efeitos e possibilidades de prevenção. In: REIS, R.A.; SIQUEIRA, G.R.; BERTIPAGLIA, L.M.A.; OLIVEIRA, A.P.; MELLO, G.M.P.; BERNARDES, T.F. (Eds.) Volumosos na produção de ruminantes. Jaboticabal: Funep, 2005. p.25-60.

SIQUEIRA, G.R.; REIS, R.A.; SCHOCKEN-ITURRINO, R.P.; BERNARDES, T.F.; PIRES, A.J.V.; ROTH, M.T.P.; AMARAL, R.C. Influência da queima e aditivos químicos e bacterianos na composição química de silagens de cana-de-açúcar. Archivos de Zootecnia, v.58, n.221, p.43-54, 2009.

SOUZA, A.L.; GARCIA, R.; PEREIRA, O.G.; P.R.; VALADARES FILHO, S.C.; PAULINO, M.F. Composição químico-bromatológica da casca de café tratada com amônia anidra e sulfeto de sódio. Revista Brasileira de Zootecnia, v.30, p.983-991, 2001. (Suplemento, 1).

SOUZA, A.L.; GARCIA, R.; PEREIRA, O.G.; CECON, P.R.; PIRES, A.V.; LOURES, D.R.S. Valor nutritivo da casca de café tratada com amônia anidra. Revista Ceres, v.49, p.669-681, 2002.

TILLEY, J.M.A.; TERRY, R.A. A twostage technique for the in vitro digestion of forage crops. Journal British of Grassland Society, v.18, p.104-111, 1963.

VAN SOEST, P.J. Development of a comprehensive system of feed analyses and its application to forages. Journal of Animal Science, v.26, p.119-28, 1967. 
Rev. Bras. Saúde Prod. Anim., Salvador, v.13, n.1, p.25-34 jan/mar, 2012 http://www.rbspa.ufba.br ISSN 15199940

VAN SOEST, P.J. Nutritional ecology of the ruminant. 2.ed. Ithaca: Cornell University, 1994. 476p.

WILSON, J.R.; KENNEDY, P.M. Plant and animal constraints to voluntary feed intake associated with fiber characteristics and particle breakdown and passage in ruminants. Australian Journal of Agricultural Research, v.47, n.1, p.199-225, 1996.
ZANINE, A.M.; SANTOS, E.M.; FERREIRA, D.J.; PEREIRA, O.G. Efeito da amonização sobre o desenvolvimento de mofos e leveduras e valor nutricional do bagaço de canade-açúcar. Revista de Biologia e Ciências da Terra, v.6, n.2, p.222-231, 2006.

Data de recebimento: $25 / 05 / 2011$ Data de recebimento: 20/12/2011 